\title{
Role of neutral wind and storm time electric fields inferred from the storm time ionization distribution at low latitudes: in-situ measurements by Indian satellite SROSS-C2
}

\author{
P. Subrahmanyam, A. R. Jain, L. Singh, and S. C. Garg \\ Radio and Atmospheric Science Division, National Physical Laboratory, Dr. K. S. Krishnan Road, New Delhi - 110 012, India
}

Received: 23 April 2004 - Revised: 5 August 2005 - Accepted: 16 September 2005 - Published: 30 November 2005

\begin{abstract}
Recently, there has been a renewal of interest in the study of the effects of solar weather events on the ionization redistribution and irregularity generation. The observed changes at low and equatorial latitudes are rather complex and are noted to be a function of location, the time of the storm onset and its intensity, and various other characteristics of the geomagnetic storms triggered by solar weather events. At these latitudes, the effects of geomagnetic storms are basically due to (a) direct penetration of the magnetospheric electric fields to low latitudes, (b) development of disturbance dynamo, (c) changes in atmospheric neutral winds at ionospheric level and (d) changes in neutral composition triggered by the storm time atmospheric heating.
\end{abstract}

In the present study an attempt is made to further understand some of the observed storm time effects in terms of storm time changes in zonal electric fields and meridional neutral winds. For this purpose, observations made by the Retarding Potential Analyzer (RPA) payload on board the Indian satellite SROSS-C2 are examined for four prominent geomagnetic storm events that occurred during the high solar activity period of 1997-2000. Available simultaneous observations, from the GPS satellite network, are also used. The daytime passes of SROSS-C2 have been selected to examine the redistribution of ionization in the equatorial ionization anomaly (EIA) region. In general, EIA is observed to be weakened 12-24 h after the main phase onset (MPO) of the storm. The storm time behaviour inferred by SROSS-C2 and the GPS satellite network during the geomagnetic storm of 13 November 1998, for which simultaneous observations are available, is found to be consistent. Storm time changes in the delay of received GPS signals are noted to be $\sim 1-3 \mathrm{~m}$, which is a significant component of the total delay observed on a quiet day.

An attempt is made to identify and delineate the effects of a) meridional neutral winds, b) the development of the ring currents and c) the disturbance dynamo electric fields

Correspondence to: P. Subrahmanyam

(manibabu@mail.nplindia.ernet.in) on the low latitude ionization distribution. The weakening of the EIA is noted to be primarily due to the decrease in the eastward electric fields driving the equatorial fountain during the daytime. The meridional neutral winds are also noted to play an important role in redistribution of ionization in the EIA region. The present results demonstrate that storm time latitudinal distribution of ionization in this region can be better understood by taking into account the meridional winds in addition to $\mathrm{E} \times \mathrm{B}$ drifts.

Keywords. Equatorial ionosphere - Ionospheric disturbances - Thermospheric dynamics

\section{Introduction}

The Climate And Weather of Sun-Earth System (CAWSES) is a new initiative by SCOSTEP. One of the objectives of this programme is to develop better understanding of the effects of solar weather events on the near-Earth environment, including the lower, middle and upper atmosphere. The space weather events refer to changes taking place in the Sun. Such events, like solar flares, coronal mass ejections (CMEs) manifest themselves as occurrences of geomagnetic storms and substorms, the appearance of auroral forms, ionospheric disturbances, etc. These events severely affect satellite communication, navigational and geo-positioning systems and therefore have led to a revival of interest in a better understanding and modelling of these effects.

There have been many efforts to understand the ionospheric effects of solar weather events triggering the geomagnetic storms (for example, see reviews by Prölss, 1995; and Danilov, 2001). The review by Prölss gives an idea of the significant progress in the understanding of ionospheric storms at mid and high latitudes. The review by Danilov summarizes various processes involved in ionospheric disturbances and also discusses the long-term trend in foF 2 and the possible contribution of the long-term variations in geomagnetic activity. The ionospheric storms at mid and high latitudes 
have been examined extensively and are relatively better understood. Only a limited number of observations are available for ionospheric effects at low and equatorial latitudes (for example, Jain et al., 1978a, b; Dabas and Jain, 1985; Dabas et al., 1989, 2003; Batista et al., 1991; Lakshmi et al., 1991; Abdu et al., 1995; Garg et al., 1996; Sobral et al., 1997, 2001; Basu et al., 2001a, b; Pincheira et al., 2002). Based on these studies it has been realised that changes at low and equatorial latitudes are significant. There have been a number of attempts to model the storm time ionospheric effects at low and equatorial latitudes, taking into account various processes, such as storm time changes in the zonal electric field, neutral wind and ion composition (Abdu et al., 1995; Fejer and Scherliess, 1995; Scherliess and Fejer, 1999; Pincheira et al., 2002; Vlasov et al., 2003; Fejer and Emmert, 2003). The storm time effects at low and equatorial latitudes can be considered in two parts: a) ionization redistribution and b) the generation of ionization irregularities, such as equatorial spread $\mathrm{F}$ (ESF) giving rise to scintillations.

The ionization redistribution at low and equatorial latitudes, in response to geomagnetic storms, is noted to be a function of storm time (i.e. time of the main phase onset (MPO) and time lapsed after the same), local time, intensity and various other characteristics of the storm. The ionization changes observed at low and equatorial latitudes consist of both positive and negative phases of the ionospheric storm. The positive phase of the storm occurs, more commonly, near the sudden commencement (SC) and the initial phase of the magnetic storm. The negative phase of the storm is generally observed with some delay $(\sim 12-24 \mathrm{~h})$ after the MPO of the storm. Sometimes the negative phase is observed on the third and fourth day of the storm, also.

A clear picture of the storm time effects at low and equatorial latitudes has just started to emerge. Some of the observed storm time effects, especially at equatorial latitudes and in the ionization anomaly region, could be explained in terms of the strengthening/weakening of the equatorial fountain due to storm time electric fields modulating the normal quiet time electric fields (Jain et al., 1978b; Dabas and Jain, 1985; Abdu et al., 1995; Sobral et al., 2001). The storm time electric fields and associated $\mathrm{E} \times \mathrm{B}$ drifts are due to: a) the change in the Interplanetary Magnetic Field (IMF), b) the development of the ring currents (which manifests itself in a sharp decrease in $\mathrm{D}_{s t}$ ) and c) the development of the ionospheric disturbance dynamo currents. The electric field, which is of magnetospheric origin, as mentioned here in a) and b), penetrates promptly to the low and equatorial latitudes, whereas the disturbance dynamo related electric field effects are delayed. The storm time electric fields of both types have been observed and the net observed effect is probably due to a combination of both types of electric fields (Batista et al., 1991; Fejer and Scherliess, 1995; Sobral et al., 1997; Vlasov et al., 2003; Fejer and Emmert, 2003). In addition to storm time changes in electric fields and associated $\mathrm{E} \times \mathrm{B}$ drifts, the meridional winds could also play a significant role in the redistribution of ionization at low and equatorial latitudes (Pincheira et al., 2002; Vlasov et al., 2003). The component of equtorward meridional wind along the field line would push the plasma upward and equatorward to lower latitudes, thus reducing the loss rate and bringing in more plasma to higher heights at lower latitudes. At the equatorial latitudes (i.e. close to geomagnetic equator) it could also result in trans-equatorial transport and a north-south asymmetry in ionization distribution. In addition to storm time changes in $\mathrm{E} \times \mathrm{B}$ drifts and meridional winds, changes in neutral composition are also sometimes invoked to explain storm time effects at low latitudes, though such changes are expected to be more prominent at high and polar latitudes (Batista et al., 1991; Prölss et al., 2002), as discussed in the later part of the paper.

The observed scintillation activity, during the early part of the night and during the dawn period, following a magnetic storm, shows considerable day-to-day variability, depending upon the state of the east-west electric field. It generally shows considerable enhancement during the post-midnight hours (Dabas et al., 1989, 1998). Paul et al. (2002), using in-situ observations from satellite SROSS-C2, observed the development of a plasma bubble, even during the low solar activity period and attributed the same to the prompt penetration of the magnetospheric electric fields equatorwards during the main phase of the magnetic storm.

Basu et al. (2001a, b) have examined the effects of three major magnetic storms in the South Atlantic Anomaly (SAA) region. They have observed prompt penetration of the magnetospheric electric fields all the way to the low latitudes, resulting in sharp changes in the Total Electron Content (TEC) and enhanced scintillation activity. It is also noted that such effects are primarily confined to a narrow longitude belt in the region of observations. This particular aspect is inferred to be due to a sharp decrease in the storm time disturbance index (Dst), coinciding with the dusk time in this sector. It is thus evident that the changes in zonal electric field affect both, i.e. the ionization distribution and also the generation of ionization irregularities at low and equatorial latitudes.

In the present study, in-situ measurements by the Indian satellite SROSS-C2 are utilized in conjunction with the delay measurements from GPS satellites, to understand the effects of prominent geomagnetic storms at low and equatorial latitudes. Four major magnetic storm events, which occurred during the high solar activity period of 1997-2000, are examined. Table 1 gives various details of the magnetic storms examined in the present study. One of the specific advantages of the SROSS-C2 satellite data is that it provides a snapshot of latitudinal distribution of the ionization and temperature for each pass and thus provides a direct insight into the ionization redistribution during magnetic storm events. An attempt is made to use these observations for a better understanding of the role of various operative mechanisms, such as changes in the east-west electric field and the background meridional winds, to the storm time ionization redistribution at the low and equatorial latitudes. 
Table 1. Details of the magnetic storm events examined in the present study.

\begin{tabular}{|c|c|c|c|c|c|c|c|c|c|c|c|c|}
\hline \multirow[b]{3}{*}{ Storm I } & \multirow{3}{*}{$\begin{array}{c}\text { Date Beginning } \\
\text { Storm }\end{array}$} & \multirow{3}{*}{$\begin{array}{c}\text { Time } \\
(\mathrm{GMT}) \\
01: 58\end{array}$} & \multirow{3}{*}{$\begin{array}{l}\text { Type } \\
\text { SC }\end{array}$} & \multirow{2}{*}{\multicolumn{2}{|c|}{$\begin{array}{c}\text { Max 3hr K-Index } \\
\text { Date Max K-Index } \\
\text { Occurrence period }\end{array}$}} & \multirow{3}{*}{$\begin{array}{c}\text { Max } \\
\text { K-Index } \\
6\end{array}$} & \multicolumn{3}{|c|}{$\begin{array}{c}\text { Change in } \\
\text { Geomagnetic Field }\end{array}$} & \multicolumn{2}{|c|}{$\begin{array}{l}\text { End Time } \\
\text { Date (GMT) }\end{array}$} & \multirow{3}{*}{$\begin{array}{c}\text { Observatory } \\
\text { Alibag }\end{array}$} \\
\hline & & & & & & & \multirow{2}{*}{$\frac{D}{6}$} & \multirow{2}{*}{$\frac{\mathrm{H}}{-}$} & \multirow{2}{*}{$\frac{\mathrm{Z}}{61}$} & & & \\
\hline & & & & 15 May 1997 & 3,6 & & & & & 17 & 1700 & \\
\hline Storm II & 7 Nov. 1998 & $08: 14$ & $\mathrm{SC}$ & 7 Nov. 1998 & 5,6 & 6 & 3 & 185 & 40 & 08 & 1600 & Alibag \\
\hline & 9 Nov. 1998 & 01:00 & - & 9 Nov. 1998 & 3,7 & 6 & 5 & 211 & 29 & 09 & 2400 & Alibag \\
\hline & 13 Nov. 1998 & 01:00 & - & 13 Nov. 1998 & $3,7,8$ & 6 & 6 & 213 & 41 & 14 & 1900 & Alibag \\
\hline Storm III & 21 Oct. 1999 & $02: 24$ & $\mathrm{SC}$ & $\begin{array}{l}22 \text { Oct. } 1999 \\
23 \text { Oct. } 1999\end{array}$ & $\begin{array}{c}1,2,3,5 \\
3\end{array}$ & & 6 & 274 & 59 & 23 & 2100 & Alibag \\
\hline Storm IV & 4 April 2000 & 08:00 & - & 4 April 2000 & $1,5,6,7$ & 5 & 4 & 141 & 42 & 04 & 2300 & Alibag \\
\hline & 6 April 2000 & $16: 39$ & $\mathrm{SC}$ & $\begin{array}{l}6 \text { April } 2000 \\
7 \text { April } 2000\end{array}$ & $\begin{array}{c}0,6,7 \\
1\end{array}$ & 7 & 11 & 384 & 56 & 08 & 0100 & Alibag \\
\hline
\end{tabular}

\section{Measurement techniques and database}

In the present study four major magnetic storm events have been selected (see Table 1). For all these events, in-situ measurements from SROSS-C2 daytime passes provide the latitudinal coverage of both equatorial as well as low latitude regions. The details of the aeronomy payload of the Retarding Potential Analyser (RPA), consisting of an electron RPA, an ion RPA and a potential probe (PP), on board SROSS-C2, are given by Garg et al. (2003) and Garg and Das (1995). The RPA measurements were carried out at a sampling interval of $22 \mathrm{~ms}$, which corresponds to a spatial resolution of $170 \mathrm{~m}$. Although the measurements were made throughout the spin cycle of the satellite, the ion sensor data taken within $\pm 30^{\circ}$ of the velocity vector of the satellite only are considered for the analysis. Measurements carried out outside the above range of angles between sensor normal and velocity vector could not be used for ion density calculations, as correction for spin modulation could not be applied outside the said limit (Garg and Das, 1995). Thus, there are a set of data points (with a $170 \mathrm{~m}$ spatial interval) covering an orbital path of about $16 \mathrm{~km}$ followed by a gap of $\sim 80 \mathrm{~km}$ and so on. However, as evident from the results presented in the next section, the SROSS-C2 provided a good latitudinal coverage. The satellite altitude for each pass and for different days of each of the magnetic storm events remained constant to within $50 \mathrm{~km}$ (see Table 2), which is about a scale height at the altitude of the satellite, thus providing a unique set of data. Table 2 includes the time interval, and the latitude and longitude range covered by each pass of the SROSS-C2, examined in the present study. In addition to the SROSS-C2 data, the $\mathrm{h}^{\prime} \mathrm{F}$ data from a ground-based ionosonde for Ahmedabad (AHD) $\left(23.02^{\circ} \mathrm{N}, 72.6^{\circ} \mathrm{E}\right)$, Kodaikanal $(\mathrm{KDK})\left(10.2^{\circ} \mathrm{N}, 77.5^{\circ} \mathrm{E}\right)$ and Trivandrum (TRV) $\left(8.55^{\circ} \mathrm{N}, 76.88^{\circ} \mathrm{E}\right)$ are used. It may be mentioned here that in India, the geomagnetic equator passes close to Trivandrum at $\sim 8.2^{\circ} \mathrm{N}$ (geog.). These three stations covered equatorial and equatorial anomaly peak latitude regions. In addition, the data on ionospheric delay from a network of GPS satellites is used. The data for the Dst index, and the equatorial electrojet strength $\left(\Delta \mathrm{Sd}_{i}\right)$, are also examined, to interpret the observations. The equatorial electrojet strength, represented by $\Delta \mathrm{Sd}_{i}$ (Kane, 1973), is computed using the $\mathrm{H}$ component of the magnetic field at Trivandrum/Tirunalveli (close to geomagnetic equator) and Alibag (reference station outside the electrojet belt). An increase in $\Delta \mathrm{Sd}_{i}$ indicates an increase in electrojet strength and vice versa.

\section{Observation results}

The observational results of each storm are discussed here.

\subsection{Storm I observations}

Figure 1a shows the plots of Dst, and $\Delta \mathrm{Sd}_{i}$ for the period of 14 May to 19 May 1997. The minimum Dst value occurred on 15 May 1997 at 13:00 GMT and the recovery phase started soon after.

Figure 2 shows the latitudinal distribution of ion density as measured by the SROSS-C2 satellite. From this figure the following features can be noted:

1. There is a well-developed anomaly on 15 May 1997, symmetric to $8^{\circ} \mathrm{N}$ (geog.), which is close to the geomagnetic equator, indicating the presence of strong eastward electric fields on this particular day. This is in contrast to an observed, weaker anomaly on 14 May 1997 , which is consistent with a weaker electrojet strength on this day, as compared to that on 15 May 1997 (Fig. 1a).

2. On 16 May 1997 the anomaly is absent and the peak in ionization is observed at $4^{\circ}-8^{\circ} \mathrm{N}$, i.e. symmetric to $\sim 6^{\circ} \mathrm{N}$ geographic (i.e. $2.2^{\circ} \mathrm{S}$ geomagnetic). The absence of an anomaly shows a weakening of the eastward electric field driving the equatorial fountain, and the shifting of symmetry to $2.2^{\circ} \mathrm{S}$ shows the presence of an equatorward meridional wind in the Northern Hemisphere. The observation of weaker equatorial electrojet strength $\left(\Delta \mathrm{Sd}_{i}\right)$ on 16 May 1997 (Fig. 1) confirms the presence of a weaker eastward electric field on this day. These two factors would contribute to more ionization 
3292 P. Subrahmanyam et al.: Neutral wind and storm time electric fields inferred from the storm time ionization distribution

Table 2. Details of the daytime SROSS-C2 observations during the period of four magnetic storm events.

\begin{tabular}{|c|c|c|c|c|c|}
\hline Storm No. & SROSS-C2 Dates & $\begin{array}{c}\text { Time Range } \\
\mathrm{h}, \mathrm{min}(\mathrm{GMT})\end{array}$ & $\begin{array}{l}\text { Time Range } \\
\quad(\mathrm{LT}, \mathrm{h})\end{array}$ & $\begin{array}{l}\text { Height Range } \\
\qquad(\mathrm{km})\end{array}$ & $\begin{array}{c}\text { Latitude \& Longitude Range } \\
\text { (Degrees) }\end{array}$ \\
\hline \multirow[t]{5}{*}{ I } & 14 May 1997 & $10,30-10,36$ & $15: 94-16: 91$ & $513.4-544.4$ & $5 \mathrm{~N}, 81 \mathrm{E}-19 \mathrm{~N}, 94 \mathrm{E}$ \\
\hline & 15 May 1997 & $10,00-10,19$ & $14: 92-16: 59$ & $486.7-539.2$ & $4 \mathrm{~S}, 71 \mathrm{E}-20 \mathrm{~N}, 91 \mathrm{E}$ \\
\hline & 16 May 1997 & $9,54-10,03$ & $14: 63-16: 21$ & $482.4-532.2$ & $2 \mathrm{~S}, 70 \mathrm{E}-21 \mathrm{~N}, 94 \mathrm{E}$ \\
\hline & 18 May 1997 & $9,23-9,30$ & $14: 12-15: 52$ & $476.7-519.8$ & $3 \mathrm{~N}, 71 \mathrm{E}-22 \mathrm{~N}, 90 \mathrm{E}$ \\
\hline & 19 May 1997 & $9,12-9,17$ & $14: 89-15: 87$ & $505.1-533.3$ & $20 \mathrm{~N}, 85 \mathrm{E}-31 \mathrm{~N}, 99 \mathrm{E}$ \\
\hline \multirow[t]{5}{*}{ II } & 8 Nov. 1998 & $9,42-9,49$ & $14: 32-15: 75$ & $588.1-572.5$ & $33 \mathrm{~N}, 69 \mathrm{E}-16 \mathrm{~N}, 89 \mathrm{E}$ \\
\hline & 10 Nov. 1998 & $9,0-9,07$ & $13: 46-14: 98$ & $588.6-578.8$ & $33 \mathrm{~N}, 67 \mathrm{E}-15 \mathrm{~N}, 88 \mathrm{E}$ \\
\hline & 11 Nov. 1998 & $8,40-8,48$ & $13: 20-14: 77$ & $587.9-579.3$ & $31 \mathrm{~N}, 68 \mathrm{E}-12 \mathrm{~N}, 89 \mathrm{E}$ \\
\hline & 14 Nov. 1998 & $7,39-7,48$ & $12: 19-14: 00$ & $583.8-582.2$ & $29 \mathrm{~N}, 68 \mathrm{E}-5 \mathrm{~N}, 93 \mathrm{E}$ \\
\hline & 15 Nov. 1998 & $7,18,7,23$ & $11: 69-12: 87$ & $580.3-585.5$ & $30 \mathrm{~N}, 66 \mathrm{E}-16 \mathrm{~N}, 82 \mathrm{E}$ \\
\hline \multirow{5}{*}{ III } & 19 Oct. 1999 & $8,45-8,54$ & $12: 84-14: 77$ & $516.9-542.0$ & $34 \mathrm{~N}, 61 \mathrm{E}-11 \mathrm{~N}, 87 \mathrm{E}$ \\
\hline & 21 Oct. 1999 & $7,49-7,58$ & $12: 47-14: 18$ & $511.8-538.3$ & $29 \mathrm{~N}, 70 \mathrm{E}-8 \mathrm{~N}, 93 \mathrm{E}$ \\
\hline & 22 Oct. 1999 & $7,21-7,29$ & $12: 20-13: 77$ & $508.4-534.7$ & $28 \mathrm{~N}, 73 \mathrm{E}-8 \mathrm{~N}, 94 \mathrm{E}$ \\
\hline & 23 Oct. 1999 & $6,53-7,1$ & $11: 91-13: 46$ & $504.4-532.4$ & $27 N, 75 \mathrm{E}-6 \mathrm{~N}, 96 \mathrm{E}$ \\
\hline & 24 Oct. 1999 & $6,23-6,32$ & $11: 17-12: 80$ & $492-523$ & $30 \mathrm{~N}, 71 \mathrm{E}-10 \mathrm{~N}, 94 \mathrm{E}$ \\
\hline \multirow[t]{5}{*}{ IV } & 3 April 2000 & $10,4-10,11$ & $14: 64-15: 93$ & $427.5-406.5$ & $25 \mathrm{~N}, 69 \mathrm{E}-7 \mathrm{~N}, 86 \mathrm{E}$ \\
\hline & 5 April 2000 & $8,51-8,58$ & $13: 63-15: 03$ & $440.7-414.5$ & $27 \mathrm{~N}, 72 \mathrm{E}-8 \mathrm{~N}, 91 \mathrm{E}$ \\
\hline & 6 April 2000 & $8,14-8,20$ & $13: 00-14: 33$ & $450.1-424.0$ & $29 \mathrm{~N}, 71 \mathrm{E}-12 \mathrm{~N}, 90 \mathrm{E}$ \\
\hline & 7 April 2000 & $9,16-9,21$ & $13: 39-14: 56$ & $439.0-416.6$ & $19 \mathrm{~N}, 62 \mathrm{E}-2 \mathrm{~N}, 78 \mathrm{E}$ \\
\hline & 10 April 2000 & $6,12-6,18$ & $11: 30-12: 42$ & $464.7-441.4$ & $19 \mathrm{~N}, 77 \mathrm{E}-2 \mathrm{~N}, 93 \mathrm{E}$ \\
\hline
\end{tabular}

at stations close to the geomagnetic equator $\left(\sim 8.2^{\circ} \mathrm{N}\right.$ geog.) and south of it, and a sharp decrease at stations north of $12^{\circ} \mathrm{N}$ geographic.

3. On 18 May the ionization anomaly reappears with a minimum ion density at $4^{\circ} \mathrm{N}$ geographic $\left(4.2^{\circ} \mathrm{S}\right.$ geomagnetic). This indicates a strengthening of the eastward electric field and the presence of an equatorward meridional wind on this day. On 19 May 1997 the anomaly appears to be fully developed again, as the ionization distribution on 19 May and 15 May 1997 matches closely.

4. An examination of temperature data from SROSS-C2 shows that the electron temperature distribution is consistent with latitudinal distribution of ionization, with a maximum value near the EIA minimum and vice versa. The ion temperature, as expected, shows lesser latitudinal variation.

The observations of storm I, thus, indicate a weakening of daytime eastward electric field following the magnetic storm and the presence of equatorward meridional winds. The meridional winds, in such circumstances, appear to play an important role by pushing the plasma upward and equatorward, and thus bringing in more ionization to stations close to the geomagnetic equator and south of it. The electron temperature distribution is noted to be consistent with the ion density distribution.

\subsection{Storm II observations}

Figure $1 \mathrm{~b}$ shows the time variation of Dst, and $\Delta \mathrm{Sd}_{i}$ for the period 08 November to 15 November 1998 . This period comprises of two events viz., one, which commenced on 9 November 1998, 01:00 GMT and another one, which commenced on 13 November 1998 at 01:00 GMT. In the case of the second event, recovery is slow and lasts longer, and hence this particular event is examined in detail. Figure 3 gives the latitudinal variation of ion density from SROSS-C2 observations for different days between 6 November 1998 to 15 November 1998. For this particular storm the ionospheric delay measurements, using a group of GPS satellites, are also available. Among these, the trajectory of a GPS satellite PRN-22 almost coincides, in time and latitude coverage, to that of SROSS-C2. Following important points may be noted.

1. The SROSS-C2 observations (see Fig. 3) clearly show that the ionization anomaly peak normally occurs between $16-20^{\circ} \mathrm{N}$ (geog.), i.e. $7.8^{\circ}-11.8^{\circ} \mathrm{N}$ (geomag.). On 14 November 1998, the day following the storm onset, not only the ionization anomaly is absent but there is also a decrease in ionization, at latitudes lower than $20^{\circ} \mathrm{N}$ (geog.). Figure 3 shows that ion density over $12^{\circ} \mathrm{N}$ latitude on the storm day, i.e. 14 November 1998 , is less by a factor of $\sim 3$ compared to that observed, say, on 11 November 1998, which is a relatively quiet day 


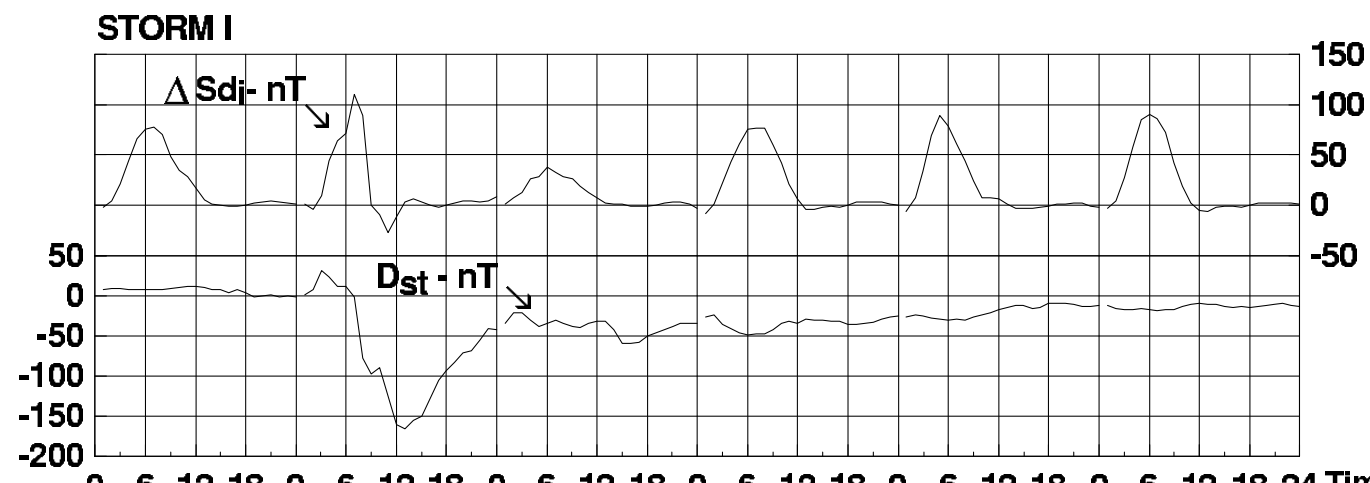

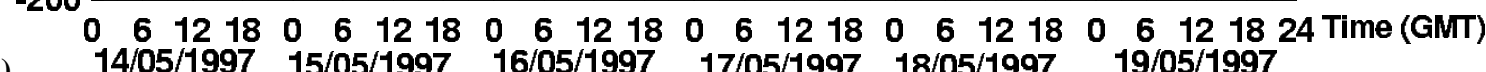

(a)

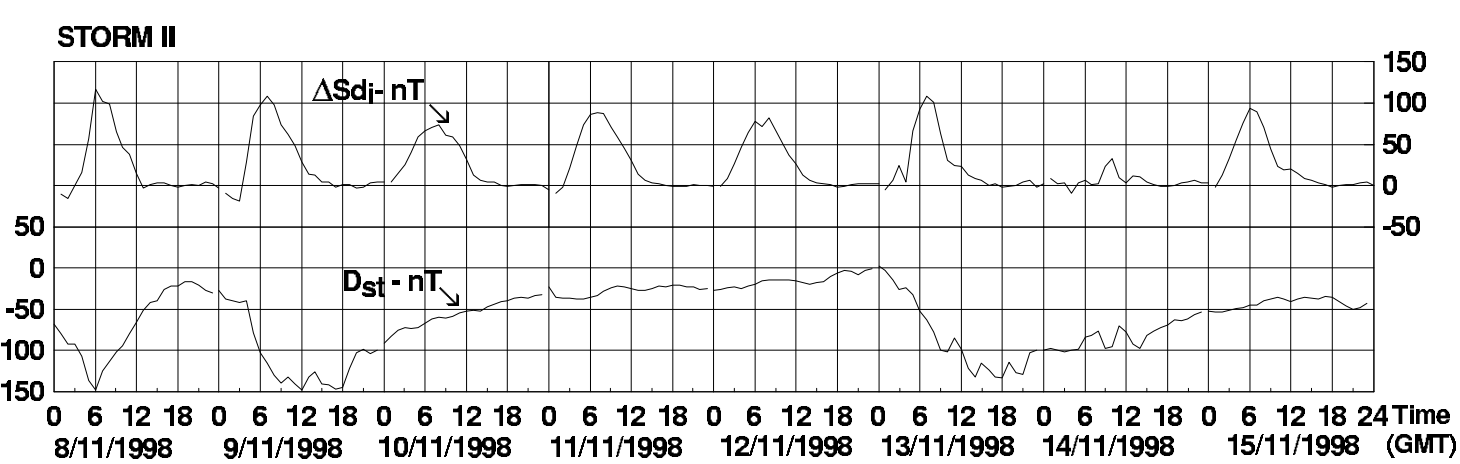

(b)

STORM III

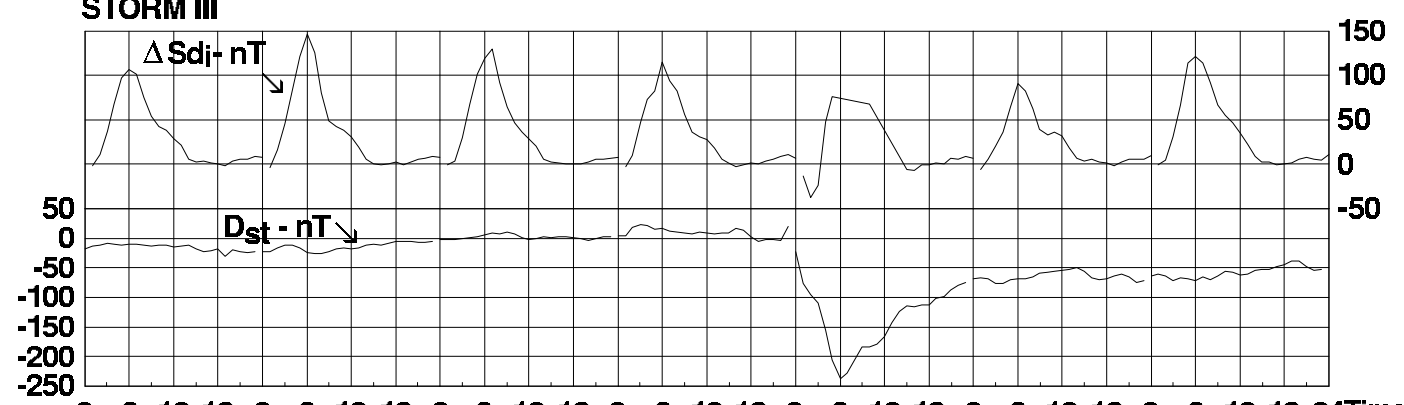

(c)

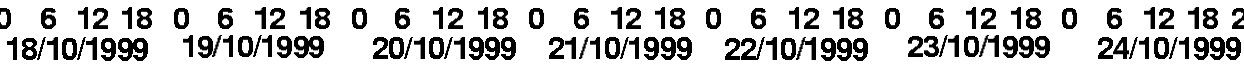

STORM IV

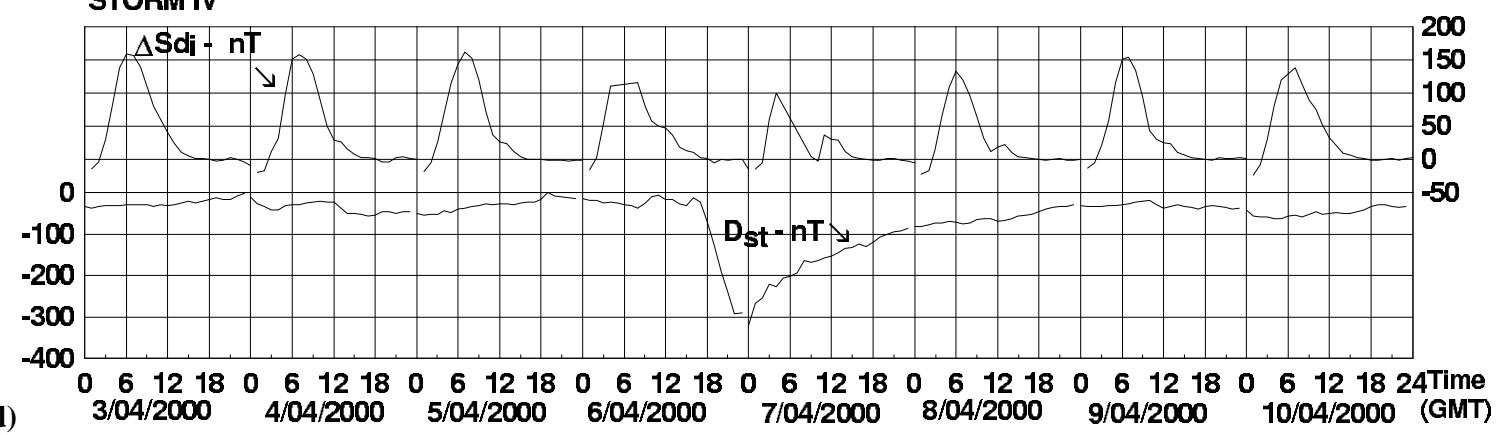

Fig. 1. Time variation of the storm time disturbance index (Dst) and equatorial electrojet strength (DSdI) during the period of storms I, II, III \& IV, respectively. 


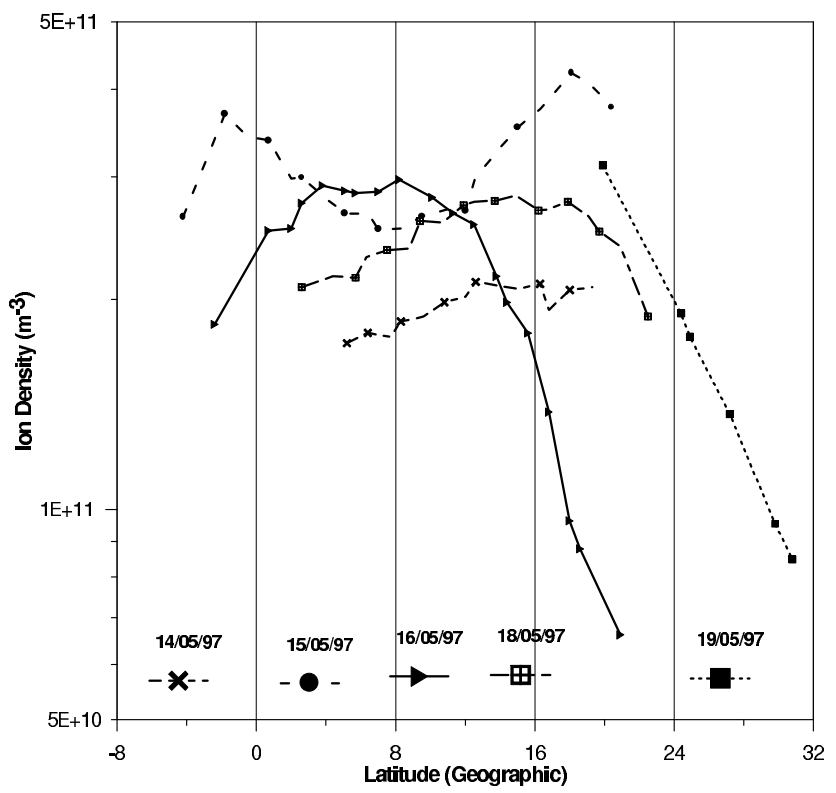

Fig. 2. Latitudinal variation of ion density observations made by the SROSS-C2 satellite during the period of storm I. The longitude range covered by each pass is given in Table 2 .

(see Fig. 1b). It may be noted from Fig. $1 \mathrm{~b}$ that $\Delta \mathrm{Sd}_{i}$ is much lower on 14 November 1998, indicating a weaker electrojet strength and eastward electric fields on this particular day. It is also noticed from Fig. 3 that on 14 November 1998 ionization is more at the latitudes beyond $24^{\circ} \mathrm{N}$ (geog.) as compared to that observed on 11 and 15 November 1998.

2. The PRN-22 GPS observations on 12, 13, 14 and 15 November 1998 are shown in Figs. 4a and b. Figure 4a shows the observed ionospheric delay as a function of time and Fig. $4 \mathrm{~b}$ shows the same as a function of the latitude (geog.). It is noted that the pass of the GPS PRN22 satellite is close to the time of the SROSS$\mathrm{C} 2$ pass (Table 2). The latitudinal plot of the ionospheric delay shows that it is smaller on 14 November 1998 by about $1-3 \mathrm{~m}$, as compared to 12,13 and 15 November 1998. This decrease in ionospheric delay on 14 November 1998 is a substantial factor $(\sim 50 \%)$ of the observed delay on other days. The latitudinal gradient of the delay on this day is also smaller as compared to the other days. Thus, GPS-PRN22 and SROSS-C2 observations are basically consistent.

3. The ionization distribution as observed on 14 November 1998 from SROSS-C2 and GPS satellites may arise due to a weakening of the eastward electric field and poleward meridional winds. On 15 November 1998, an ionization anomaly peak appears again at the latitude between $16-18^{\circ} \mathrm{N}$ (geog.). This is expected as the storm recovery starts on 13 November at 18:00 GMT and completely recovers by 15 November 1998 at 09:00 GMT and seen from the plots in Fig. $1 b$.

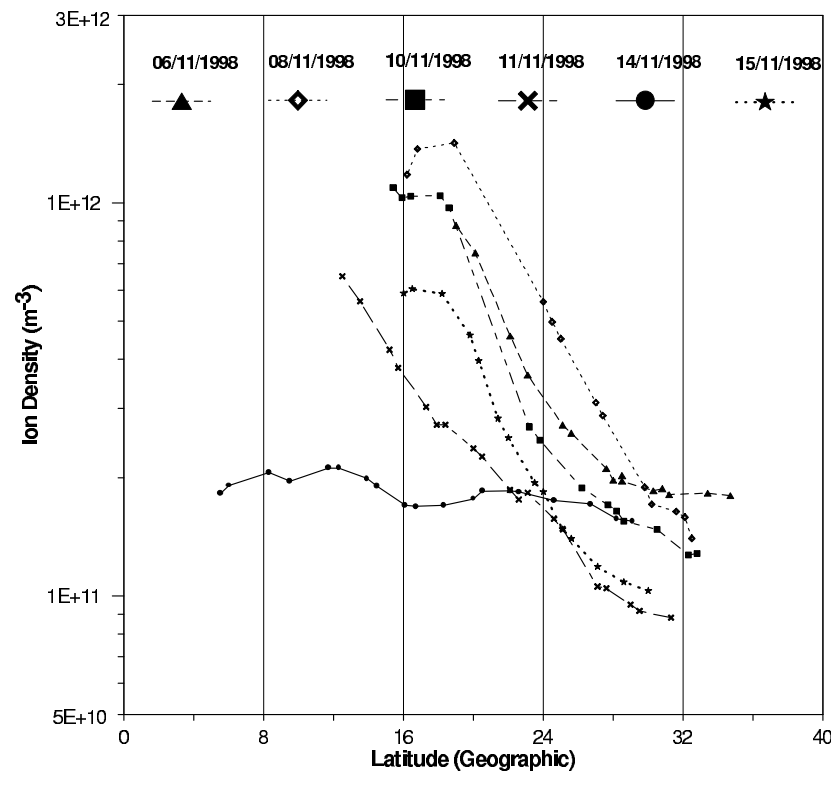

Fig. 3. Latitudinal variation of ion density observations made by the SROSS-C2 satellite during the period of storm II. The longitude range covered by each pass is given in Table 2 .

\subsection{Storm III observations}

Figure $1 \mathrm{c}$ shows the time variation of the Dst, and $\Delta \mathrm{Sd}_{I}$ for the period of 18 October 1999 to 23 October 1999. This particular storm started on 22 October 1999 at 00:00 GMT and the Dst reached a maximum depression on 22 October 99 at 06:00 GMT (11:30 IST), with a minimum value of $\mathrm{D}_{s t} \sim-250 \mathrm{nT}$. The recovery phase starts soon after this. Figure 5 shows the latitudinal variation of ion density as observed by SROSS-C2 on days between 19 October 1999 to 24 October 1999. The following points are noted from observations presented in Figs. 1c and 5:

1. The ionization anomaly peak appeared at $22^{\circ} \mathrm{N}$ (geog.), i.e. $13.8^{\circ} \mathrm{N}$ (geomag.), before the onset of the storm (i.e. on 19 October 1999). After the onset of the geomagnetic storm, the anomaly peak is seen to move equatorward. The anomaly peak on 22 and 23 October 1999 appears at $\sim 15^{\circ} \mathrm{N}$ (geog.). The peak ion density on 23 October 1999 is also relatively lower.

2. From the plot of the equatorial electrojet strength for this particular storm (see Fig. 1c) it is clear that a weaker equatorial electrojet strength $\left(\Delta \mathrm{Sd}_{i} \sim 75 \mathrm{nT}\right)$ is observed on 22 and 23 October 1999 which shows that the eastward electric field on these two particular days is relatively weaker. Thus, the weaker eastward electric field could explain the weaker EIA on these two days.

3. The results presented in Fig. 5 show that on 22 and 23 October 1999 the decrease in ion density with latitude, north of anomaly peak, is relatively less as compared to that observed on 19 and 21 October 1999. A smaller ion density decrease, with latitude at locations 
north of anomaly peak, on 22 and 23 October 1999, indicates the presence of a poleward wind moving plasma from the stations near the anomaly peak, northward and downward, as discussed later in the paper.

\subsection{Storm IV observations}

Figure $1 \mathrm{~d}$ shows the time variation of Dst and $\Delta \mathrm{Sd}_{i}$ for 3 April 2000 to 10 April 2000. This particular storm started at $\sim 15: 00$ GMT (20:30 IST) on 6 April 2000. The minimum Dst value $\sim-300 \mathrm{nT}$ is observed at about 00:00 GMT on 7 April 2000. The recovery phase starts soon after 00:00 GMT. Figure 6 shows the latitudinal variation of ion density as observed by SROSS-C2 from 3 April 2000 to 10 April 2000. From this figure the following important points can be noted.

1. On relatively magnetically quiet days, the equatorial ionization anomaly (EIA) peak appears at about $24^{\circ} \mathrm{N}$ Geog. (15.8 $\mathrm{N}$ geomag.) and the minimum between $7-10^{\circ} \mathrm{N}$ geog. (i.e. $1.2^{\circ} \mathrm{S}$ to $1.8^{\circ} \mathrm{N}$ geomag.). Following the onset of the magnetic storm on 6 April 2000, the ionization at low latitude, i.e. between $2-18^{\circ} \mathrm{N}$ geog. (i.e. $6.2^{\circ} \mathrm{S}-9.8^{\circ} \mathrm{N}$ geomag.), is noted to be considerably enhanced (by a factor of 2 or more) on 7 April 2000 , indicating that on this particular day, the anomaly is shallower as compared to the other days. This seems to be the case even if the ionization on this day at latitudes close to the anomaly peak (i.e. $\sim 20^{\circ} \mathrm{N}$ geog.) remains more or less the same.

2. The plot of the equatorial electrojet strength $\left(\Delta \mathrm{Sd}_{i}\right)$ in Fig. 1d shows that the electrojet is relatively weaker on 7 April 2000. This is consistent with the shallower EIA observation from SROSS-C2 data and indicates that eastward electric field driven $\mathrm{E} \times \mathrm{B}$ drifts are weaker on this day.

3. In addition to the weakening of EIA, it is also observed that the ion density on 7 April 2000 is enhanced between $2^{\circ}-18^{\circ} \mathrm{N}$ (geog.), i.e. $6.2 \mathrm{~S}-9.8 \mathrm{~N}$ (geomag.) latitude region, where a maximum observed ion density enhancement also appears to be near the geomagnetic equator or slightly south.

\section{Discussion}

The SROSS-C2 observations have a distinct advantage over the ground-based measurements, as they provide a snapshot of the latitudinal distribution of low and equatorial ionization distribution. Simultaneous observations of delay using the GPS satellite, during the storm II period, also shows a significant storm time decrease in the observed delay.

Some of the observed storm time changes, especially during the negative phase of the storm, could partly be due to storm time changes in the composition i.e., $\mathrm{O} / \mathrm{N}_{2}$ ratio. However, such changes are expected to be more prominent at auroral and high latitudes and the effects of such changes generally decrease with a decrease in latitude. Therefore, the

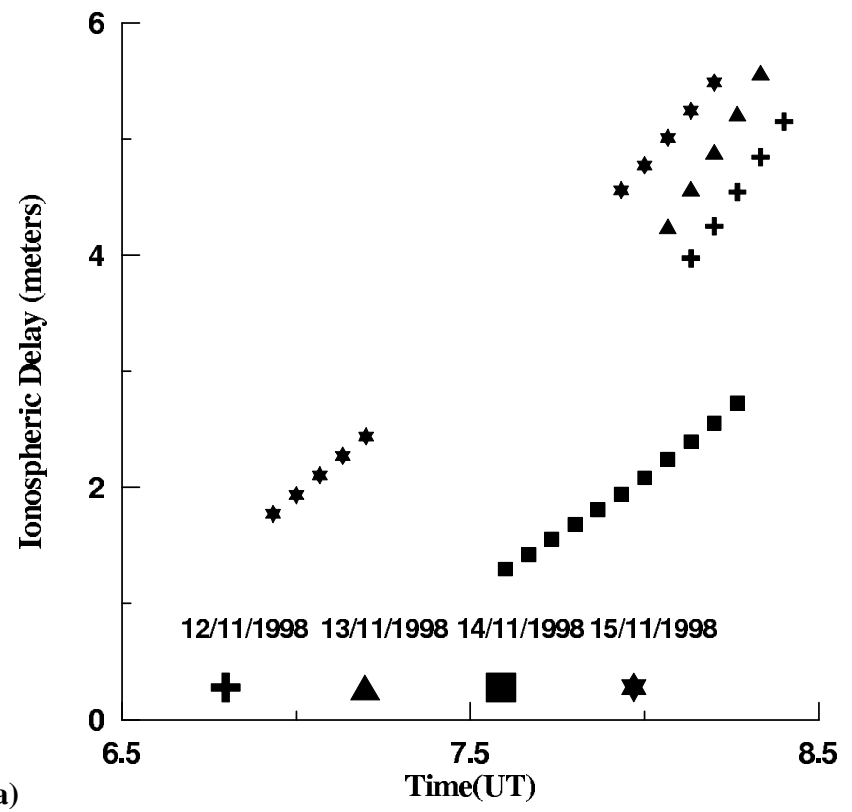

(a)

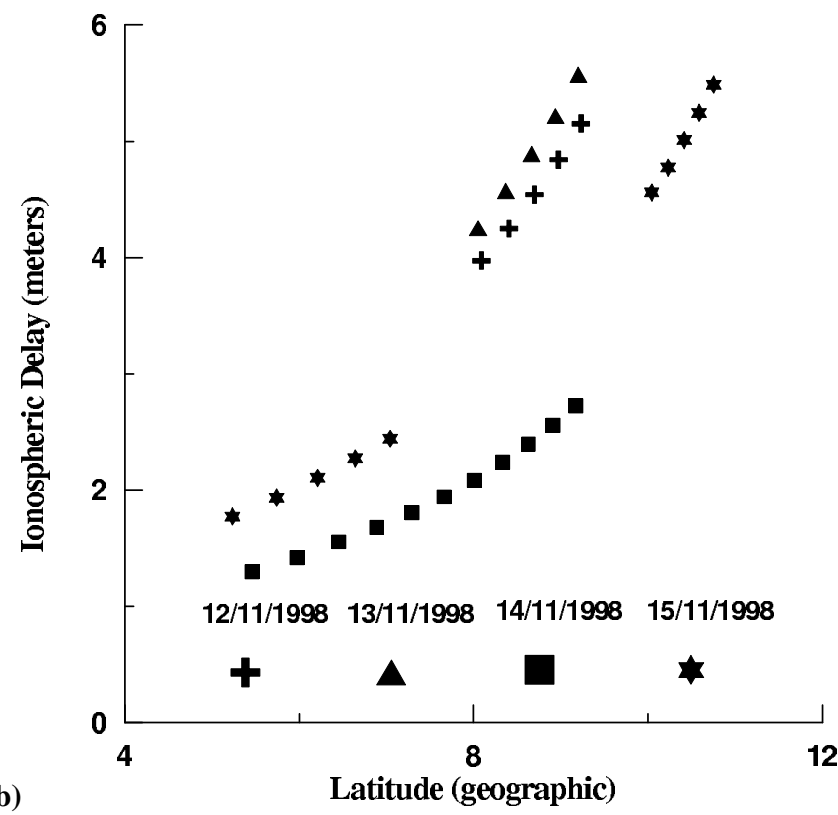

Fig. 4. Observation of ionospheric delay made using satellite GPS PRN22 at Bangalore, (a) time variation, (b) latitudinal variation on different days during storm II.

contribution of these changes at low and equatorial latitudes are expected to be relatively smaller (Lakshmi et al., 1991; Prölss, 1995; Prölss et al., 2002). The negative phase of the storm at low and equatorial latitudes can also arise due to changes in the zonal electric field and associated $\mathrm{E} \times \mathrm{B}$ drifts, and due to changes in the meridional winds. These two mechanisms are expected to play a more direct and significant role at low latitudes, especially in the EIA region. In the present discussions, therefore, SROSS-C2 measurements have been utilized to better understand the role of neutral winds and storm time electric fields in the storm time 


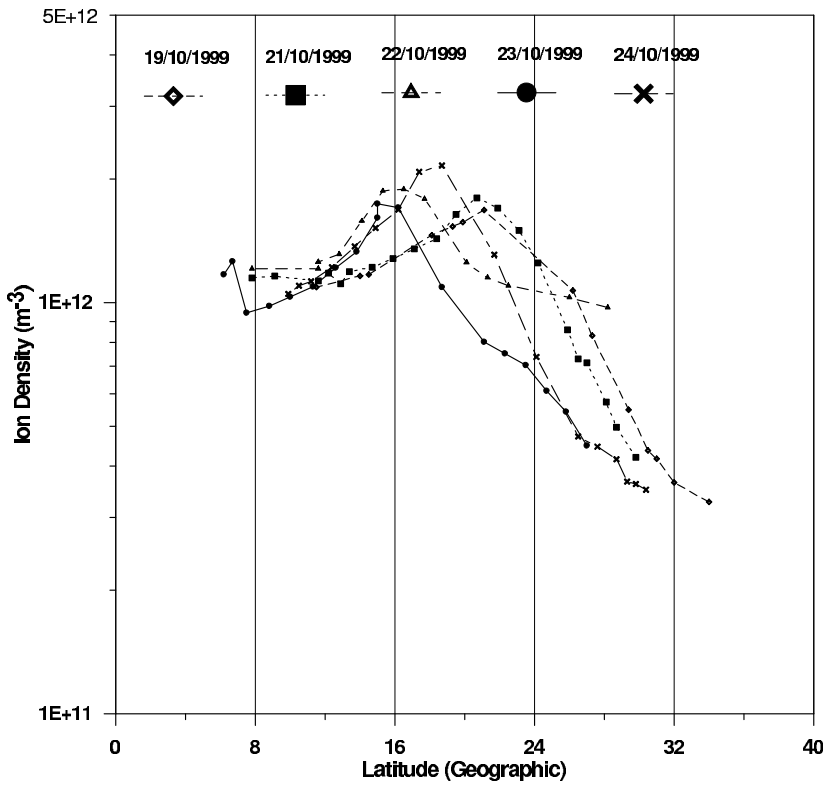

Fig. 5. Latitudinal variation of ion density observations made by the SROSS-C2 satellite during the period of storm III. The longitude range covered by each pass is given in Table 2 .

ionization distribution at the low latitudes.

\subsection{Contribution of storm time electric fields}

In the present study, the latitudinal distribution of ionization during daytime is examined. The electric fields associated with ring current development and decay manifest as a sharp decrease in Dst magnitude, followed by a recovery phase. The electric fields associated with a to disturbance dynamo also appear at low and equatorial latitudes, but after a delay ranging from $12-24 \mathrm{~h}$ after storm main phase onset. The $\mathrm{E} \times \mathrm{B}$ drifts associated with the electric fields at low latitudes appear to explain largely the daytime ionization redistribution and changes in EIA.

The storm time heating at E-region heights in the auroral region gives rise to a change in the winds and the development of the disturbance dynamo at these levels. The net effect of these electric fields associated with a disturbance dynamo is the sharp reduction of EIA for all four storms. Simultaneous observation of the equatorial electrojet confirms that the reduction in EIA is due to a weakening of the eastward electric field driving the equatorial fountain. However, present observations show that the weakening of the EIA does not always result in an increase of the ionization at the equator (geomagnetic) and near the equatorial stations, as expected. Out of the four storms that are examined here, two storms (storm I and IV) have shown enhancement in ionization at equatorial latitudes, whereas in one case (storm II) a clear decrease in ionization is observed. In the case of storm III, the EIA is observed to be weakened and has moved closer to the geomagnetic equator after the onset of the storm, with no significant change in ionization at the equatorial latitude.

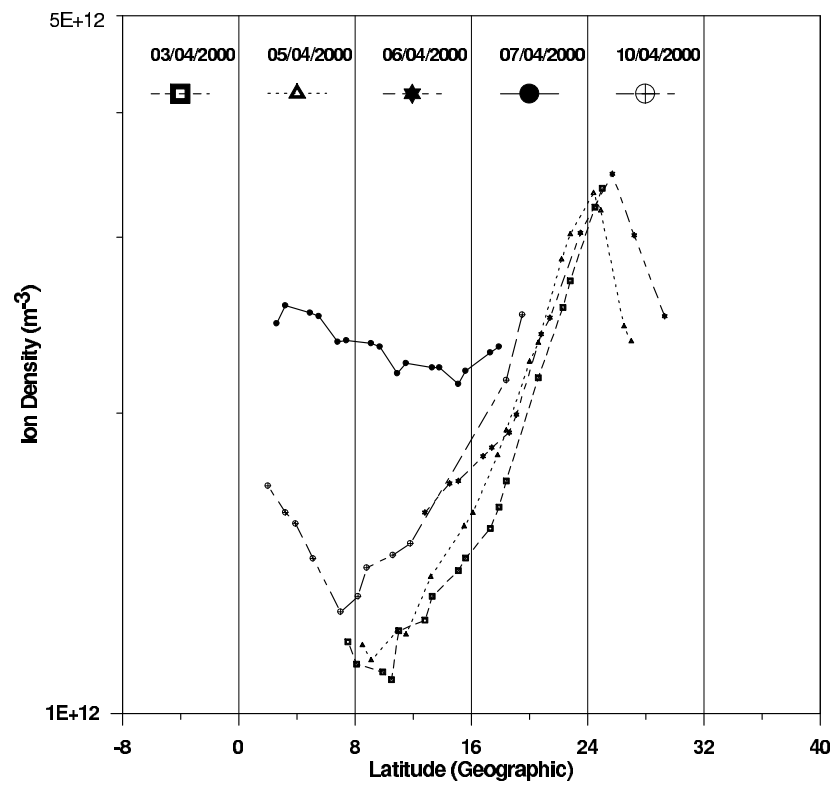

Fig. 6. Latitudinal variation of ion density observations made by the SROSS-C2 satellite during the period of storm IV. The longitude range covered by each pass is given in Table 2 .

Observations of all the storms are consistent with the weakening of the eastward electric fields, which appears to be due to the modulation of normal dynamo field (eastward) by the disturbance dynamo field (westward).

The $\mathrm{E} \times \mathrm{B}$ drifts have been suggested to play a major role at low and equatorial latitude ionization distribution by many workers (Jain et al., 1978b; Dabas and Jain, 1985; Abdu et al., 1995; Sobral et al., 2001). The electric field of magnetospheric origin promptly penetrates to the low latitude, and the effects of the disturbance dynamo associated electric fields occur with some delay. The actual observed $\mathrm{E} \times \mathrm{B}$ drifts are perhaps the net effect of the two types of electric fields, as suggested by Fejer and Scherliess (1995), Sobral et al. (1997), Pincheira et al. (2002), Fejer and Emmert (2003). The recent observations by Sastri et al. (2002) have also shown a penetration of the westward electric field disturbance during midnight in the Indian sector, corresponding to the observation of the eastward electric field disturbance during dusk in the American sector, as reported by Basu et al. (2001a) for the severe geomagnetic storm of 15 July 2000. The westward electric field and associated downward drifts would result in an increase in the loss rate and a faster decay of ionization at low latitudes. The present observations and those reported by Basu et al. (2001a) and Sastri et al. (2002) are generally consistent with the ideas of Abdu et al. (1995).

\subsection{Contribution of meridional neutral winds}

The role of $\mathrm{E} \times \mathrm{B}$ drifts is very much evident from the present series of observations. It is also evident that all the features cannot be explained in terms of $\mathrm{E} \times \mathrm{B}$ drifts alone and hence it is also necessary to invoke other mechanisms to explain vari- 
ous observed effects. The possible contribution of meridional winds during magnetic storms at these latitudes has been postulated by many workers (for example, Jain et al., 1978b; Dabas and Jain, 1985; Pincheira et al., 2002; Vlasov et al., 2003). The present series of observations by SROSS-C2, as discussed below, show that the meridional neutral winds also play an important role in the ionization distribution at these latitudes.

The electric field and meridional winds both contribute to the vertical drifts of the ionospheric plasma. At stations with dip angle $I$, the net vertical drift $\boldsymbol{V}_{\boldsymbol{Z}}$, due to these two contributions, is given by:

$\boldsymbol{V}_{\boldsymbol{Z}}=\boldsymbol{V}_{\boldsymbol{E}} \cos I+\boldsymbol{V}_{\boldsymbol{H}} \sin I \cos I$,

where $V_{E}$ is $\mathrm{E} \times \mathrm{B}$ drift perpendicular to the field line (positive upward due to eastward electric field) and $V_{H}$ is the meridional wind. An equtorward meridional wind would have an upward and southward component. In the Eq. (1) upward drift $\left(V_{Z}\right)$ is considered to be positive. The eastward electric field and an equtorward wind would both contribute to the upward drift. A reduction in both the eastward electric field and a poleward wind would contribute to the reduction in upward drift. For this purpose $h^{\prime} F$ at Ahmedabad and Trivandrum/Kodaikanal is examined. Figure 7 gives the plots of the $h^{\prime} F$ values at Ahmedabad (AHD) and at Trivandrum/Kodaikanal (TRV/KDK). The latter are the two equatorial stations. In this figure $h^{\prime} F$ values are plotted for each day of storm I to storm IV. These are the mean values corresponding to the local time interval of the SROSS-C2 pass on the day of the maximum storm effect for each storm (i.e. 16 May 1998 for storm I, 14 November 1998 for storm II, 23 October 1999 for storm III and 7 April 2000 for storm IV). The local time range for the SROSS-C2 satellite pass for each day of the storm is given in Table 2. The effects of meridional winds for each day of the storm are discussed below.

\section{Storm I}

In this storm the anomaly is well developed on 15 May 1997 and it is almost symmetric to the geomagnetic equator $\left(8.2^{\circ} \mathrm{N}\right.$, geog.). On 16 May 1997, that is a day after the main phase onset (MPO), the anomaly is noted to be absent. The peak of ionization on this day is noted to be symmetric to $6^{\circ} \mathrm{N}$ (geog.) or $+2.2^{\circ} \mathrm{S}$ (geomag.). The ionization density at geomagnetic equator, on 16 May 1997, has increased from $\sim 2.5 \times 10^{11} \mathrm{~m}^{-3}$ to $\sim 3.0 \times 10^{11} \mathrm{~m}^{-3}$. These observations indicate a weakening of the eastward electric field and the appearance of an equatorward meridional wind on this day. The net effect of these two factors on $V_{Z}$, as evident from Eq. (1), would depend on the magnitude of $\mathrm{V}_{E}$ and $\mathrm{V}_{H}$. The net upward drift would push the layer upward at stations like Ahmedabad. The $h^{\prime} F$ at Ahmedabad (AHD) on 16 May 1997 is relatively higher as compared to that observed on 14 and 15 May 1997, indicating that the effect of the equatorward wind is prominent (see Fig. 7). On 18 May 1997, though a weak anomaly is observed,
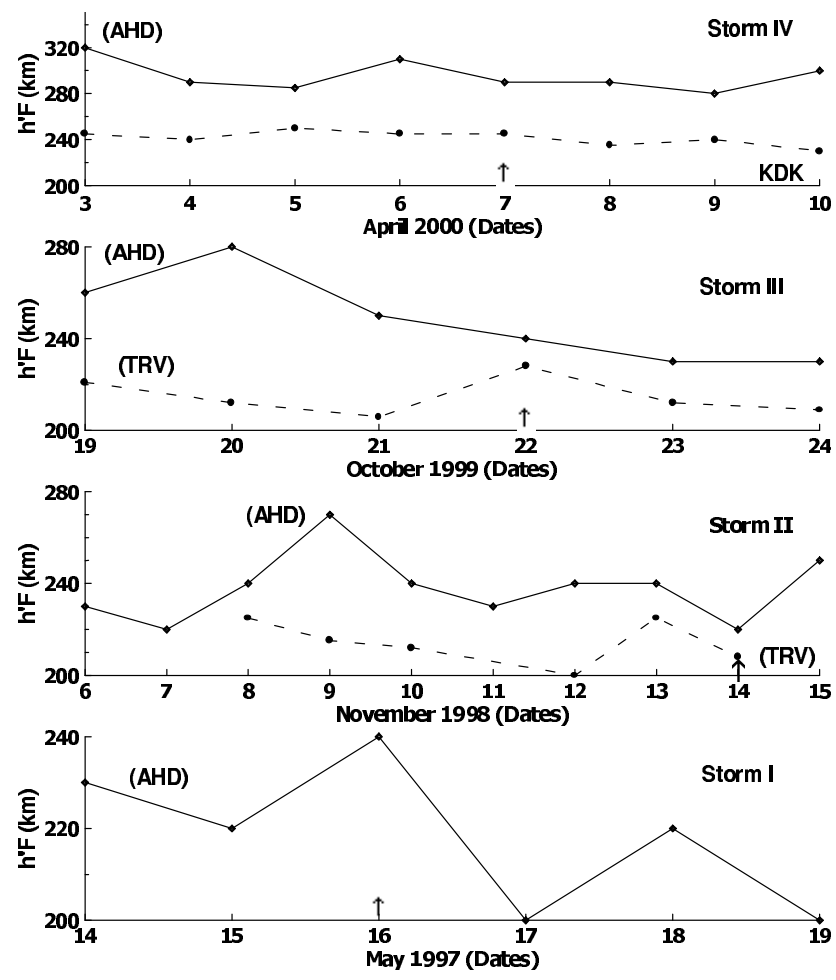

Fig. 7. The figure gives the plots of $h^{\prime} F$ at Ahmedabad (AHD) and at Trivandrum/Kodaikanal (TRV/KDK) during the period of storms I to IV. The latter (TRV/KDK) are the two equatorial stations. The plotted $h^{\prime} F$ values for each day of storm I to storm IV are the mean values corresponding to the local time (IST) interval of the SROSSC2 pass on the day of the maximum storm effect (i.e. 16 May 1998 for storm I, 14 November 1998 for storm II, 23 October 1999 for storm III and 7 April 2000 for storm IV). The SROSS-C2 satellite pass local time for each day of the storm are given in Table 2 .

the minimum ion density is observed at $\sim 4^{\circ} \mathrm{N}$ (geog.), again indicating the persistence of an equatorward wind.

\section{Storm II}

In this particular storm MPO is on 13 November 1998. On 14 November 1998, the anomaly is observed to be absent and the ionization density on this particular day, as observed by SROSS-C2, at locations close to the geomagnetic equator, i.e. at $10^{\circ} \mathrm{N}$ (geog.), is smaller by a factor of 3 as compared to that on 11 November 1998 (see Fig. 3). In contrast, the ion density at stations greater than $20^{\circ} \mathrm{N}$ remains more or less unchanged. Therefore, the question is, What has caused this decrease in daytime ionization, at the SROSS-C2 altitude, at equatorial and low latitudes? The equatorial electrojet intensity index $\Delta \mathrm{Sd}_{i}$ shows that the eastward electric field is much weaker on 14 November 1998 This should have resulted in an enhancement in ionization at locations close to the geomagnetic equator, as the equatorial fountain would be weaker. Hence, in order to explain the reduction of ionization, as observed on this day, it is suggested that a prevailing poleward wind 
would sweep the plasma from the equatorial and low latitudes to higher latitudes ( $\geq 20^{\circ} \mathrm{N}$, geog.). Together, a weakening of the eastward electric field and poleward wind would result in the reduction of the height $\left(h^{\prime} F\right)$ of the layer (see Eq. (1)) at stations like Ahmedabad. This is confirmed from Fig. 7. The value of $h^{\prime} F$ at Ahmedabad on 14 November 1998 is relatively low compared to the other days.

\section{Storm III}

The SROSS-C2 observations for this particular storm show that EIA is weaker and the anomaly peak has moved towards the equator. Normally, the peak appears at about $22^{\circ} \mathrm{N}$, whereas on 22 and 23 October 1999, it is observed to be between $14-16^{\circ} \mathrm{N}$ (geog.). This is an indication of the presence of weaker eastward electric fields, as discussed earlier. There is no substantial change in ionization at stations near the geomagnetic equator. The rate of decrease of ionization with latitude, north of the anomaly peak, on 22 and 23 October 1999, is much smaller as compared to the other days (see Fig. 5). The type of latitudinal distribution of ionization observed on 22 and 23 October 1999 can be due to the combined effect of a weaker eastward electric field and the presence of a poleward wind. The poleward wind would sweep away the plasma from the location close to the anomaly peak and move the same plasma to stations north of anomaly peak. The decrease in the eastward electric field and the presence ofthe poleward wind, together, are expected to cause a decrease in $h^{\prime} F$ at higher latitude stations, say, at Ahmedabad. This is also confirmed from ground-based observations presented in Fig. 7.

\section{Storm IV}

The main phase onset (MPO) for this particular storm occurred on 6 April 2000. The SROSS-C2 observations for this particular storm show that on 7 April 2000, i.e. one day after the MPO, the ionization anomaly is shallower and a substantial increase in ionization (by a factor of more than 2) is noticed on this day with maximum enhancement at the locations close to the geomagnetic equator $\left(8.2^{\circ} \mathrm{N}\right.$ geog. $)$ and south of it.

It is suggested that this type of change in ion density distribution can be brought in by the combined effect of a) a decrease in the eastward electric field and b) the development of an equatorward wind. On this day, the net changes in $h^{\prime} F$ at station like Ahmedabad would depend on a) the decrease in the eastward electric field and on $b$ ) the increase due to the equatorward wind. The $h^{\prime} F$ at Ahmedabad on 7 April 2000, as compared to 6 April 2000, is somewhat lower. This indicates that, perhaps, the effects due to the decrease in the eastward electric field are dominant (see Fig. 7).

The results of the observation by satellite SROSS-C2 thus show that at low and equatorial latitudes, though the effect of $\mathrm{E} \times \mathrm{B}$ drifts are dominant, the meridional neutral winds also contribute significantly to the observed storm time changes in the distribution of ionization. Among the four storms, for the October and November storms, signatures of poleward winds are noted. In contrast, for April and May storm, equatorward meridional winds are noted, though the magnitude of such a wind appear to be relatively small. This is consistent with the model calculations of the meridional winds, which predict a daytime equatorward wind prevailing in the summer Northern Hemisphere and a poleward wind during the winter Northern Hemisphere (Lei et al., 2003). Therefore, the present results show that while modelling storm time effects at low and equatorial latitudes, it is necessary to take into account both the changes in the meridional neutral wind and the zonal electric field.

\section{Conclusions}

1. The disturbance dynamo related changes in the electric fields appear $12-24 \mathrm{~h}$ after storm onset and also contribute to the redistribution of ionization through changes in the $\mathrm{E} \times \mathrm{B}$ drifts. The contribution of the disturbance dynamo related electric field is to modulate the daytime eastward electric field by the westward electric field, which results in the weakening of EIA at the low and equatorial latitudes.

2. It is also noted that, though $\mathrm{E} \times \mathrm{B}$ drifts contribute significantly to the redistribution of ionization at these latitudes, to explain the observed distribution of ionization at these latitudes, it is necessary to invoke other mechanisms. The changes in $\mathrm{E} \times \mathrm{B}$ drifts, combined with meridional winds, appear, to a large extent, to explain the present observations.

3. The results presented here clearly demonstrate the advantage of the SROSS-C2 measurements in better understanding the low latitude ionization distribution.

Acknowledgements. The authors would like to thank the director of the Indian Institute of Geomagnetism, Mumbai for providing the geomagnetic data for Alibag, Trivandrum and Tirunelveli stations used in the present study. Thanks are also due to H. Chandra, Physical Research Laboratory, Ahmedabad, R. Sridharan, Director of the Space Physics Laboratory, Trivandrum and J. H. Sastri, Director of the Indian Institute of Astrophysics, Bangalore, for providing Ionosonde data for Ahmedabad, Trivandrum and Kodaikanal respectively. The GPS data for Bangalore was downloaded from the IGS website (ftp://cddisa.gsfc.nasa.gov). We also thank K. G. M. Pillai for his help in compilation of the data for some of the storm events. A. R. Jain is thankful to the Department of space, Government of India, for providing support as ISRO visiting scientist at NPL.

Topical Editor M. Lester thanks M. Vlasov and another referee for their help in evaluating this paper. 


\section{References}

Abdu, M. A., Batista, I. S., Walker, G. O., Sobral, J. H. A., Trivedi, N. B., and de Paula, E. R.: Equatorial ionospheric electric fields during magnetospheric disturbances: local time/longitude dependences from recent EITS campaign, J. Atmos. Solar Terr. Phys., 57, 1065-1083, 1995.

Basu, S., Basu, S., Groves, K. M., Yeh, H. C., Su, S. Y., Rich, F. J., Sultan, P. J., and Keskinen, M. J.: Response of the equatorial ionosphere in the South Atlantic region to the great magnetic storm of July 15, 2000, Geophys. Res. Lett., 28, 3577-3580, 2001a.

Basu, S., Basu, S., Valladares, C. E., Yeh, H. C., Su, S. Y., Mackenzie, E., Sultan, P. J., Aarons, J., Rich, F. J., Doherty, P., Groves, K. M., and Bullett, T. W.: Ionospheric effects of major magnetic storms during the International Space Weather Period of September and October 1999: GPS observations, VHF/UHF scintillations, and in situ density structures at middle and equatorial latitudes, J. Geophys. Res., 106, 30 389-30 413, 2001 b.

Batista, I. S., de Paula, E. R., Abdu, M. A., Trivedi, N. B., and Greenspan, M. E.: Ionospheric effects of the March 13, 1989, Magnetic storm at low and equatorial latitudes, J. Geophys. Res., 96, 13 943-13 952, 1991.

Dabas, R. S. and Jain, A. R.: Geomagnetic Storm Effects in Ionospheric TEC at an Equatorial Station: Contribution of $\mathrm{E} \times \mathrm{B}$ Drifts and Meridional Neutral Winds, Indian J. Radio and Space Phys., 14, 100-106, 1985.

Dabas, R. S., Lakshmi, D. R., and Reddy, B. M.: Effect of geomagnetic disturbances on the VHF night-time scintillation activity at equatorial and low latitudes, Radio Sci., 24, 563-573, 1989.

Dabas, R. S., Lakshmi, D. R., and Reddy, B. M.: Day-to-day variability in the occurrence of equatorial and low-latitude scintillations in the Indian zone, Radio Sci. 33, 89-96, 1998.

Dabas, R. S., Lakha, S., Lakshmi, D. R., Subrahmanyam, P., Chopra, P., and Garg, S. C.: Evolution and dynamics of equatorial plasma bubbles relationships to $\mathrm{E} \times \mathrm{B}$ drift, postsunset total electron content enhancements, and equatorial electrojet strength, Radio Sci., 38, 1075, doi:10.1029/2001RS002586, 2003.

Danilov, A. D.: F2-region response to geomagnetic disturbances, J. Atmos. Solar Terr. Phys., 63, 441-449, 2001.

Fejer, B. G. and Emmert, J. T.: Low-latitude ionospheric disturbance electric field effects during the recovery phase of the 1921 October 1998 magnetic storm, J. Geophys. Res., 108, 1454, doi:10.1029/2003JA010190, 2003.

Fejer, B. G. and Scherliess, L.: Time dependent response of equatorial ionospheric electric fields to magnetospheric disturbances, Geophys. Res. Lett., 22, 851-854, 1995.

Garg, S. C. and Das, U. N.: Aeronomy Experiment on SROSS-C2, J. Spacecraft Technology, 5, 11-15, 1995.

Garg, S. C., Anand, J. R., Bahl, M., Subrahmanyam, P., Rajput, S. S., Maini, H. K., Chopra, P., John, T., Singhal, S. K., Vishram, S., Dhan, S., Das, U. N., Bedekar, S. M., Soma, P., Venkateswarlu, S. and Goel, D. P.: RPA aeronomy experiment onboard the Indian satellite SROSS-C2 - Some important aspects of the payload and satellite, Indian J. Radio and Space Phys., 32, 5-15, 2003.

Garg, S. C., Subrahmanyam, P., Bahl, M., Maini, H. K., Chopra, P., Singhal, S. K., John, T., Rao, B. C. N., and Somayajulu, Y. V.: Incidence of extensive plasma density depletions in the lower Fregion, Adv. Space Res., 18, 103-106, 1996.
Jain, A. R., Deshpande, M. R., Sethia, G., Rastogi, R. G., Malkiat, S., Gurm, H. S., Janve, A. V., and Rai, R. K.: Geomagnetic storm effects on ionospheric total electron content in Indian zone, Indian J. Radio and Space Phys., 7, 111-118, 1978a.

Jain, A. R., Deshpande, M. R., Sethia, G., Rastogi, R. G., Malkiat, S., Gurm, H. S., Janve, A. V., and Rai, R. K.: Geomagnetic storm effects on ionospheric total electron content in Indian zone - Part II: Evidence of equatorial electrojet control through fountain effect, Indian J. Radio and Space Phys., 7, 254-261, 1978 b.

Kane, R. P.: An estimate of the equatorial electrojet strength, J. Atmos. Terr. Phys., 35, 1565-1567, 1973.

Lakshmi, D. R., Rao, B. C. N., Jain, A. R., Goel, M. K., and Reddy, B. M.: Response of equatorial and low latitude F-region to the great magnetic storm of 13 March 1989, Ann. Geophys., 9, 286290, 1991.

Lei, J., Liu, L., Luan, X., and Wan, W.: Model study on neutral winds in the ionospheric F-region and comparison with the equivalent winds derived from the Wuhan Ionosonde data, TAO, 14, 1-12, 2003.

Paul, A., Ray, S., DasGupta, A., and Garg, S. C.: First in-situ observations of equatorial ionosphere bubbles by Indian satellite SROSS-C2 and simultaneous multi-satellite scintillations, Radio Sci., 37, 1087, doi:10.1029/2001RS002519, 2002.

Pincheira, X. T., Abdu, M. A., Batista, I. S., and Richards, P. G.: An investigation of ionospheric responses, and disturbance thermospheric winds, during magnetic storms over South American sector, J. Geophys. Res., 107, 1379, doi:10.1029/2001JA000263, 2002.

Prölss, G. W.: Ionospheric F-region storms, Handbook of Atmospheric Electrodynamics, 2, edited by: Volland, H., CRC Press, Boca Raton, FL, 195-248, 1995.

Prölss, G. W. and Werner, S.: Vibrationally excited Nitrogen and Oxygen and the origin of negative ionospheric storms, J. Geophys. Res., 107, doi:10.1029/2001JA900126, 2002.

Sastri, J. H., Niranjan, K., and Subbarao, K. S. V.: Response of the equatorial ionosphere in the Indian (midnight) sector to the severe magnetic storm of July 15, 2000, Geophys. Res. Lett., 29, doi:10.1029/2002GL015133, 2002.

Scherliess, L. and Fejer, B. G.: Radar and satellite global equatorial F region vertical drift model, J. Geophys. Res., 104, 6829-6842, 1999.

Sobral, J. H. A., Abdu, M. A., Gonzalez, W. D., Tsurutani, B. T., Batista, I. S., and Clua de Gonzalez, A. L.: Effects of intense storms and substorms on the equatorial ionosphere/thermosphere system in the American sector from ground-based and satellite data, J. Geophys. Res., 102, 14 305-14313, 1997.

Sobral, J. H. A., Abdu, M. A., Cristina, S., Yamashita, Gonzalez, W. D., de Gonzalez, A. C., Batista, I. S., Zamulutti, C. J., and Tsurutani, B. T.: Response of the low-latitude ionosphere to very intense geomagnetic storms, J. Atmos. Solar Terr. Phys., 63, 965-974, 2001.

Vlasov, M., Kelley, M. C., and Kil, H.: Analysis of ground-based and satellite observation of F-region behavior during the great magnetic storm of July 15, 2000, J. Atmos. Solar Terr. Phys., 65, 1223-1234, 2003. 